\title{
The Effect of English Passive Voice Learning on the Use of "Bei" Structure: An Empirical Study
}

\author{
Min $\mathrm{CaO}^{1}$ \\ ${ }^{1}$ School of Foreign language studies, Henan Polytechnic University, Jiaozuo Henan, China \\ Correspondence: Min Cao, School of Foreign language studies, Henan Polytechnic University, Jiaozuo Henan, \\ China. E-mail: cmada@hpu.edu.cn
}

Received: May 3, 2016 Accepted: May 30, 2016 Online Published: July 13, 2016

doi:10.5539/ijel.v6n4p197 URL: http://dx.doi.org/10.5539/ijel.v6n4p197

\begin{abstract}
This paper conducts an empirical investigation among English foreign language (EFL) learners at a university in China, mainly on their understanding of the passive voice in their native language to verify the existence of backward transfer in their first language (L1) environment and how backward transfer may relate to the learners' proficiency of second language (L2) English and L1 Chinese in the sentence translation task (STT) and discourse task (DT) of Chinese paragraph writing. The study shows that backward transfer does exist at STT or sentence level in L1 environment. Additionally, the Chinese participants at intermediate English proficiency level are likely to experience backward transfer from L2 English to L1 Chinese. Moreover, for EFL learners at the lower and top English proficiency level no obvious signs of backward transfer shown at the sentence level. And all of the EFL participants have not been influenced by L2 English in the Chinese discourse task. The results of this study convey the complexity of backward transfer and its interactions with L1 and L2 proficiency and different tasks.
\end{abstract}

Keywords: backward transfer, passive voice, sentence translation task, discourse task

\section{Introduction}

Language transfer, applying one's knowledge from one language to another language (Weinreich, 1953) has been broadened by recent researches from different directions, that the second language influences the first or what sometimes is called "reverse transfer" or "backward transfer"(Cook, 2003). Several areas of language, from pragmatics to lexis and morphology were investigated, for example at phonetic (Zinszer et al., 2015), morphsyntactic (Balcom, 2003), lexical (Laufer, 2003), semantic (Pavlenko, 2003), pragmatic (Abu-Rabia, 2013), rhetorical (Kecskes \& Papp, 2000), and conceptual (Kesckes \& Papp, 2003) level. Most of the studies on the influence of the L2 on the L1, collected by Cook (2003), usually refer to L1 speakers living in the L2 community. According to Cook's multi-competence theory (1991), the compound state of a mind with two grammars, foreign language learners and users in the first language environment might experience backward transfer, or in other words, their first language might be influenced by their foreign language.

Since English is an obligatory course for Chinese students, they spend a certain amount of time studying English. It seems that the Chinese L2 learners' L1 Chinese could be influenced by their L2 English, that is, the backward transfer may occur in native language or first language environment. Only recently, some researchers began to pay attention to the real existence of backward transfer in Chinese students' Chinese production. Wang (2006) used nominal constructions beyond inflection phrase (IP) as examples to prove that the transference may be both from L1 to L2 and from L2 to L1, that is the existence of two-way language transference. Based on the translation principles, Zhang et al. (2006) examined two ill-translated sentences and revealed the L2 influence on L1, and they called such an influence L2 effect in direct translation. The relationship between backward transfer and their language proficiency have to be further discovered in more relevant researches.

In this study, an empirical investigation was conducted to test whether the English-like Chinese passive voice (Bei structure) in the EFL learners' writing is the result of English to Chinese backward transfer, and how backward transfer in general may relate to the Chinese learners' L2 English proficiency and L1 Chinese proficiency in sentence and discourse tasks. 


\section{The Current Study}

\subsection{Participants}

In this research, 104 university students, EFL learners at their first year are invited to complete the questionnaires. These students enrolled at the university through the National Entrance Examination (NEE). They took English as one of the main subjects in their middle school and high school education, with at least 5 English classes per week. After they were admitted into the university, they devoted a certain amount of their time to studying English besides their usual four-hour English classes per week. All of the participants are class-instructed English learners in China. Based on their English scores in the NEE, specifically, Level 1 participants obtain English scores in the 100-114 range, Level 2 participants in the 116-124 range, and Level 3 participants in the 126-133 range. Meanwhile, in order to access the possible effects of L1 Chinese proficiency on language transfer, the subjects are also divided into three proficiency levels according to their Chinese scores in the NEE. Level 1 participant have Chinese scores in 100-104 range, and Level 2 in the 105-110 range, Level 3 participants obtain 110-126 range. Because it is a Polytechnic University, their Chinese and English scores cover a wide range.

\subsection{Instrument}

The questionnaire is composed of two tasks including one sentence translation task and a discourse task, a writing test according to the given pictures. In the STT, the subjects are asked to translate English sentences into Chinese. Because of the factors like time and learners' contemporary linguistic proficiency, only twenty representative sentences are chosen from the examples in Wang's book (2004). As has been indicated in his book, in English and Chinese the passive can be considered from the cognitive perspective as to include two categories: the prototypical and non-prototypical passive. In task one, 20 prototypical passive sentences are chosen. It is natural for us to translate the agentless passive from English into Chinese Bei construction because they share the central functions of prototypical passives. But only those English passives in which the verbs are prototypical transitive verbs can be translated into Bei construction because prototypical verbs not only impinge on the patient but also cause a change in it. For example:

Children should be taught to speak the truth. 应该教导儿童讲实话。

(Poor translation: 儿童被应该教导讲实话) (Wang, 2004)

It would be odd for us to translate the above agentless passive into Chinese Bei construction because no change has been caused in the subject of the passive and no result is implied. Because the passives express a causative event with the agent absent, we should translate them into Chinese subjectless actives. The other two sentences are also the case:

\section{Teachers may be asked questions. 可以向老师提问。}

What language is spoken there? 那里讲什么语言?

In Chinese, if the patient is the subject of the sentence definitely, the Bei can be omitted. For example, “鸡杀了”, “书出版了”, “贼抓住了”, among the 20 sentences in the translation test, 11 sentences belong to this kind. So there are 14 sentences should be translated into non-Bei construction. Among the other 6 sentences, 2 should be translated into Chinese pattern “是... 的”, 2 sentences should be added the agent somebody, the other 2 sentences are objective clauses.

In the discourse task, the EFL learners are asked to describe the event in the following six sequential pictures by using 100-150 words. The participants are guided to explain what has happened to the motorcyclist in each picture, it is hoped that they will use at least four Bei structures in their narration of the pictures at the discourse level. Accordingly, there will be a probable number of 240 tokens for the 60 participants $(4 * 60)$ to produce either the passive structure or active structure at the discourse level. Then, dividing the actual tokens of Bei structure use by the 240 possible tokens will reveal the EFL learners' preference for processing information at the discourse level. Out of the total data base, a statistical corpus was established on 60 eligible cases. The subjects are divided into three levels according to their Chinese and English scores in the National Entrance Examination. The data computation was carried out by means of SPSS and EXCEL software for frequency accounts, correlation analysis, One-Way ANOVA tests, Chi-Square test.

\subsection{Procedure}

The experiment was carried out at their English class, and the whole experiment took 45 minutes to finish. As there are two tasks in the experiment, the aim of the STT is to investigate learners' actual production of the passive voice in L1, in order to ensure the reliability of the results, the translation test was arranged to be the first 
task. The data collection was manipulated by the author.

Firstly, the subjects were given two pieces of paper: one with instruction and the twenty sentences on it and the other the picture-given task. After the instruction was read aloud and explained to the subjects, they were required to translate the twenty English sentences into Chinese and write down their answers on the blank space of the paper within 25 minutes. When time was up, the answers were handed in. Secondly, the subjects were presented with second task to finish. After the instructions were explained, the students wrote a story about the picture. Before analyzing the data, the researcher read through the 104 answer sheets, and eliminated those unqualified translations such as those sentences which were not completed. In the end, 60 valid pieces of translation and their corresponding tasks were taken for data analysis.

During the process of data collection, great care had to be taken for fear that the participants would intentionally pay attention to grammatical structures. In addition, the production test-translation was arranged before the other task. They were told that their translation would be evaluated on the basis of complete expression of the meaning. The instructions were given by the teacher in Chinese so that the participants could fully understand the requirements. Besides, there would be no passive voice in Chinese in the instructions given by the teacher, and in this way they had to rely on their own linguistic resources to express their ideas in Chinese.

\subsection{Data Analysis}

We begin with analyzing the STT part, since it is the first task the subjects were asked to fulfill. At first, we need to know how the English prototypical and non-prototypical passives are translated by the subjects. The frequencies of the passive use adopted by the subjects in translating every sentence were also figured out through dividing the frequency of the passive use of every sentence by the total number of the subjects chosen for data analysis. We also computed the percentage of the correct translation, which was obtained through dividing the frequency of the correct translation by the total number of the passive use of every sentence. As for the correctness, in this research the translation with the Bei-construction in Chinese as its predicate was considered to be incorrect, except the first sentence, which has to be translated into a Chinese one with Bei. Besides, if the subjects used other verbs like verbs gei, rang to replace the verb Bei, it was still to be considered incorrect as long as the sentence includes the complete structure of the passive in Chinese. However, if the passive was used in the sentence where a passive use was regarded improper in Chinese, the sentence was correspondingly translated incorrectly. With the help of Excel, we finally got the table in the Appendix, and based on that table, Figure 1 was drawn which gave us a more clear idea of the distribution of non-Bei construction use and the correct non-Bei construction use among the subjects.

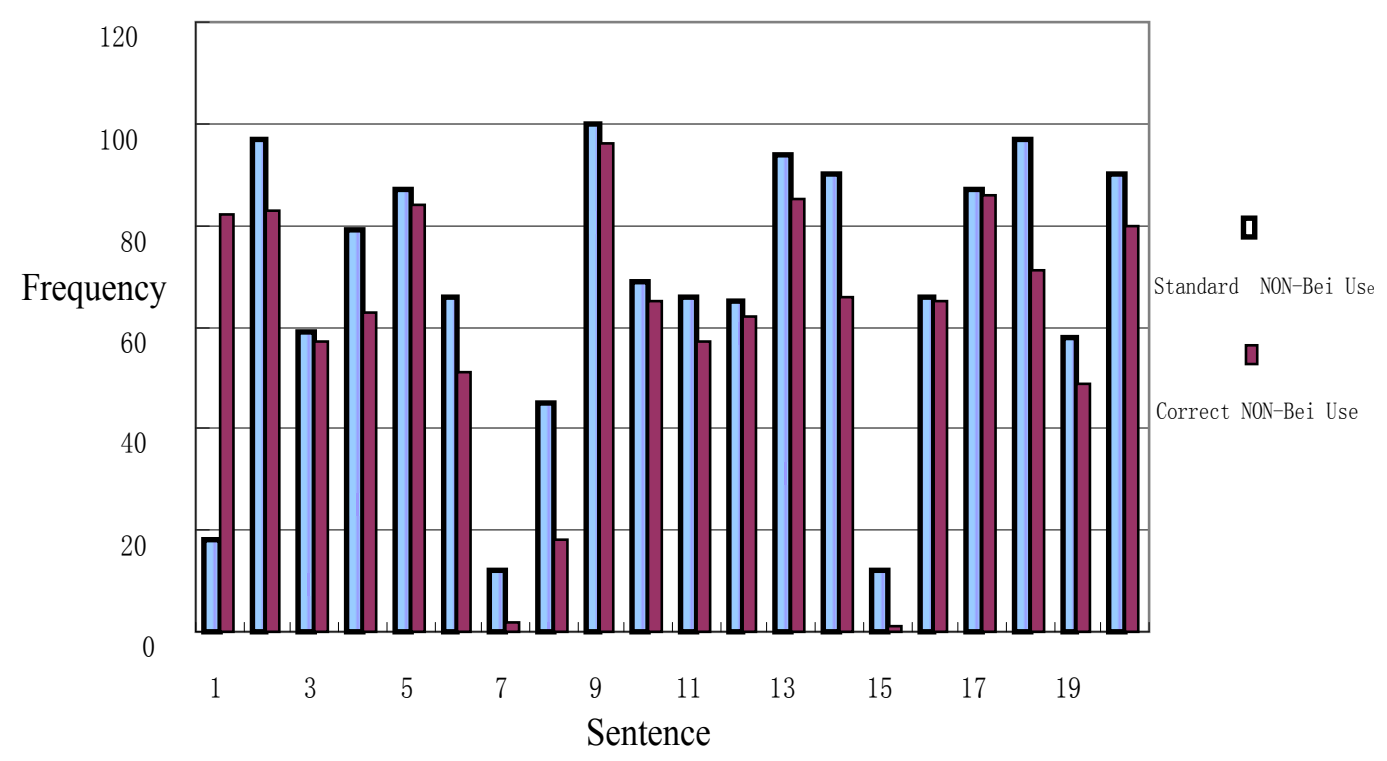

Figure 1. Distribution of non-Bei construction use and its correct use

From this figure, it is clear that the prototypical sentences, in which the subject is the object of the transitive verb 
in active Chinese, are likely to be translated into non-Bei structure in Chinese. For example, the ninth sentence "What language is spoken there?" takes the first place, the eighteenth "Those characters were written by him." is in the second place and the fourteenth "The violin was made by my father." the fifth place. It is noticeable that those sentences are more likely to be ranked in the front places, but the percentages of the correct use of the non-passive in the translation of these sentences are not that high as expected. Just take the second, fifth and eighteenth sentences for example. Although they are close to the foreside area in the sequence, the percentage of correct use is comparatively low.

From the subjects' translation, it is found that most of the translated Chinese sentences have some different errors. Then based on the percentage of correct translation in each sentences, in order to get further evidence of the manifestations of backward transfer, errors in the production by the subjects were also analyzed. Since the correct use and its percentage have been presented in the table in the Appendix, the following part mainly concentrates on errors committed by the subjects. Through our analysis, it is found that there are several types of errors by learners in their production of the translation:

(1) Using the passive voice in the sentence in which the passive voice is considered to be improper:

\section{The house is being built. *房子正在被建设。}

The window needs to be repaired. *夏子需要被修理。

(2) Using incorrect time adverbs in the translation.

The house is being built. *房子盖好了。

(3) Using incorrect language patterns in the translation.

The violin was made by my father. *父亲创造了小提琴。

Since the first error is the manifestation of backward transfer in Chinese learners' Chinese, we pay no attention to the other errors in the students' answer sheet. In the following part, we will use the SPSS 13.0 to analyze the correlation between L2 English, L1 Chinese proficiency and the EFL learners' actual use of non-Bei structure in their L1 writing at the sentence and discourse levels separately.

\section{Results and Discussion}

Based on the data collected on the questionnaires and the relative statistics analyzed, findings are merged as follows

\subsection{The Relation between Backward Transfer and L2 English Proficiency}

The overall performances in the Chinese EFL learners' L1 Chinese STT and Chinese DT across three English proficiency levels is first provided in relative frequency distributions and followed by significant tests as shown in Table 1 and Table 2 correspondingly.

Table 1. The relative frequency in the EFL learners' Bei pattern and non-Bei pattern use in the Chinese STT across three English proficiency levels

\begin{tabular}{|c|c|c|c|c|}
\hline participants & The Chinese STT & & The Chinese DT & \\
\hline $\begin{array}{l}\text { Translation } \\
\text { structures }\end{array}$ & Non-passive structure & Passive structure & Non-passive structure & Passive structure \\
\hline Level 1 & $76.32 \%$ & $23.68 \%$ & $78.75 \%$ & $21.25 \%$ \\
\hline Level 2 & $54.74 \%$ & $45.26 \%$ & $77.5 \%$ & $22.5 \%$ \\
\hline Level 3 & $82.11 \%$ & $17.89 \%$ & $78.75 \%$ & $21.25 \%$ \\
\hline
\end{tabular}

As displayed in Table 1, the Chinese EFL learners exhibit different use of non-Bei and Bei construction at different L2 English proficiency levels in both the STT and DT. To prove if the differences among the three subgroups have statistically significant differences, Chi-Square are further conducted and the results shown in Table 2. 
Table 2. The relationship between the use of non-Bei structure among the Chinese EFL groups and L2 English proficiency in the Chinese STT and Chinese DT

\begin{tabular}{|c|c|c|c|c}
\hline participants & \multicolumn{2}{|c|}{ The Chinese STT } & \multicolumn{2}{c}{ The Chinese DT } \\
\hline $\begin{array}{c}\text { Translation } \\
\text { structures }\end{array}$ & $\begin{array}{c}\text { Non-passive } \\
\text { structure }\end{array}$ & $\begin{array}{c}\text { Passive } \\
\text { structure }\end{array}$ & $\begin{array}{c}\text { Non-passive } \\
\text { structure }\end{array}$ & Passive structure \\
\hline Leve1 1 & $76.32 \%$ & $23.68 \%$ & $78.75 \%$ & $21.25 \%$ \\
\hline Leve1 2 & $54.74 \%$ & $45.26 \%$ & $77.5 \%$ & $22.5 \%$ \\
\hline Leve1 3 & $82.11 \%$ & $17.89 \%$ & $78.75 \%$ & $21.25 \%$ \\
\hline \multicolumn{7}{|c|}{ Chi-Square } & df & \multicolumn{3}{c}{ Asymp.sig } \\
\hline Tasks & 34.056 & 2 & .000 \\
\hline Chinese STT & 140 & 932 \\
Chinese DT
\end{tabular}

As indicated in Table 2, there is a significant L2 proficiency effect in the Chinese STT $(0.000<0.05)$, but not in the Chinese DT $(0.932>0.05)$. In the following part, inferential statistical tests are further carried on to find out the possible difference among the three L2 proficiency levels.

In the Chinese STT, further statistical results using the One-Way ANOVA display a significant difference between Level 1 and Level 2; Level 2 and Level 3 subgroups in the Chinese STT. However, there is no significant difference between L1 and Level 3 subgroups. That is, the negative L2 effect on Chinese passive voice caused the low frequency of use the non-Bei structure in Level 2 participants' production. In other words, the negative L2 effect is most visible in the Level 2 L2 English learners. There is no significant L2 effect can be found in Chinese EFL learner's performance of non-Bei pattern in DT.

Table 3. The significant difference of using non-Bei structure among the three English proficiency levels of the Chinese EFL learners in the Chinese STT

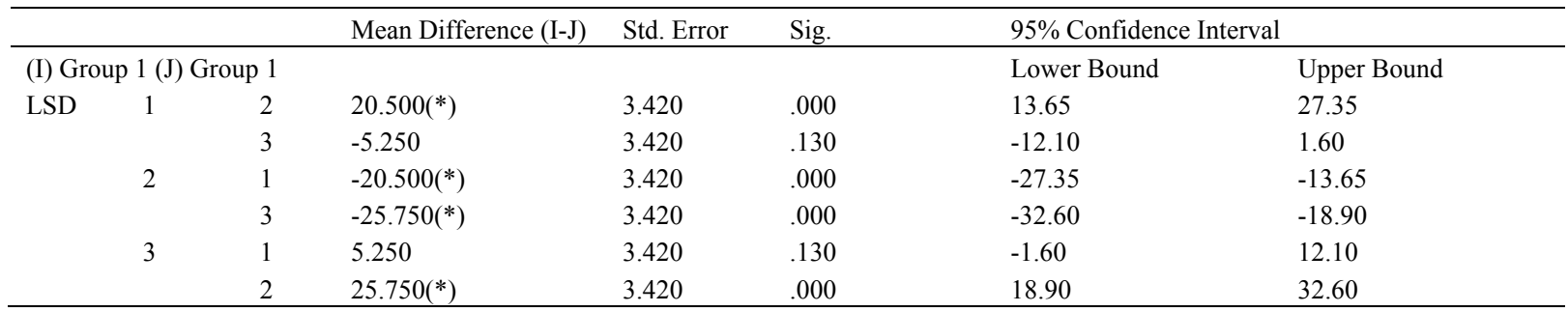

As displayed earlier in Table 1, across the three L2 English proficiency levels in the Chinese STT, the frequency rate of correct use non-Bei structure is $76.32 \%$ at level one, $54.74 \%$ at level two, and $82.11 \%$ at level three. It is quite conspicuous that the frequency rate at level two is only $54.74 \%$, which is comparatively low, with the other two levels, level one and level three, which are $76.32 \%$ and $82.11 \%$. The minimal difference between Level 1 and Level 3 and the vast difference between Level 1 and Level 2, Level 2 and Level 3 show that why there is no significant difference between Level 1 and Level 3. In this way, the Chinese EFL learners will experience a negative backward transfer from their L2 English passive voice to their L1 Chinese passive voice, particularly the use of the non-Bei structure to express the passive voice in their Chinese STT when their L2 reaches the Level 2 proficiency level. In other words, the Chinese participants at Level 2 English proficiency level are likely to experience backward transfer from L2 English to L1 Chinese.

\subsection{The Relation between Backward Transfer and L1Chinese Proficiency}

In order to see whether there is some correlation between EFL Learners' first language proficiency and their test scores in this paper, we divided the subjects into three Chinese proficiency levels. Their relative frequencies in the performance on the Chinese STT across three Chinese proficiency levels are indicated in Table 4. 
Table 4. The relative frequencies in the Chinese EFL learners' Bei pattern and non-Bei pattern use in the Chinese STT across three Chinese proficiency levels

\begin{tabular}{lllll}
\hline participants & The Chinese STT & \multicolumn{3}{l}{ The Chinese DT } \\
\hline $\begin{array}{l}\text { Translation } \\
\text { structures }\end{array}$ & Non-passive structure & Passive structure & Non-passive structure & Passive structure \\
Level 1 & $70.26 \%$ & $29.74 \%$ & $78.75 \%$ & $21.25 \%$ \\
Level 2 & $71.58 \%$ & $28.42 \%$ & $77.5 \%$ & $22.5 \%$ \\
Level 3 & $71.32 \%$ & $28.68 \%$ & $73.75 \%$ & $26.25 \%$ \\
\hline
\end{tabular}

As displayed in Table 4, the statistics show that the Chinese EFL learners nearly use the same amount of non-Bei structure at three L1 Chinese proficiency levels in both the Chinese STT and Chinese DT. The minimal difference among them conveys no significant difference among the three Chinese proficiency levels. To testify the differences among the three Chinese subgroups, Chi-Square are further conducted as indicated in table 5.

Table 5. The relationship between the use of non-Bei structure among the Chinese EFL groups and L1 Chinese proficiency in the Chinese STT and Chinese DT

\begin{tabular}{llll}
\hline Tasks & Chi-Square & df & Asymp.sig \\
\hline Chinese STT & .061 & 2 & .970 \\
Chinese DT & .455 & 2 & .797 \\
\hline
\end{tabular}

As shown in Table 5, inferential statistics reveals no significant L2 proficiency effect in the Chinese STT $(0.970>0.05)$ and the Chinese DT $(0.797>0.05)$.

\section{Conclusion}

\subsection{Summary}

This experiment has investigated the possible existence of backward transfer in Chinese L1 environment; the hypothesis predicts that there is a relationship between L2 proficiency and the use of the L1 non-Bei structure in the Chinese EFL learners' L1 writing. The inferential statistics display that the participants at all English and Chinese proficiency levels use predictable number of non-Bei structure in the Chinese DT. However, in the Chinese STT, the Chinese EFL learners at the three proficiency levels perform quite differently, especially participants at Level 2. As displayed in Table 1 and Figure 2, English Level 2 learners experience a negative L2 influence on their performance in the Chinese STT, because of the less use of the non-Bei structure by the English Level 2 Chinese learners in the STT. While they are found to use non-Bei structures equally at all Chinese proficiency levels. In their first translation task (STT), the Level 2 English proficiency learners use their obviously less L1 non-Bei structures than the Level 1 and Level 3 learners. Their underuse of their L1 non-Bei structure in the Chinese STT and overuse of English-like structure Bei structure needs to be explained.

\subsection{Implication}

Several implications arise from this investigation of Chinese EFL learners' use of passive voice at the sentence and discourse levels in their Chinese writing.

\subsubsection{Theoretical Implication}

The development of EFL learners' writing proficiency should be regarded as a vital part in their in L1 and L2 language education. The previous study shows that the EFL learner will experience backward transfer from their L2 to their L1. Accordingly, a great number of relative theoretical questions emerge, what kind of knowledge will be transferred backward? And when the EFL learners will reach the L2 level? How to avoid the negative backward transfer and promote the positive backward transfer to help the EFL learners succeed in both languages? Cummins' the threshold level hypothesis (1976) states that there are two thresholds, lower threshold and higher threshold. Once the bilingual users have a high level in one of the languages, or the lower threshold level of bilingual competence is achieved, no negative cognitive effect exist. Whereas once they reach high levels in both languages or the higher threshold level is achieved, positive cognitive effects do exist. It seems that Cummins' theory explains the reason for the negative and positive bidirectional transfer, but as it is criticized the two thresholds are not sufficiently defined. And in this study how to define the level 2 EFL learners, it will be a good point to discuss the reasons of the existence of backward transfer or bidirectional transfers. 


\subsubsection{Methodological Implication}

More recent researches suggest that different levels of analysis should be examined at the same time. This study covers the students' performance of passive voice at sentence level (STT) and discourse level (DT). It is conspicuous that if this study was done only at sentence level, these isolated findings would have led to a different conclusion. Furthermore, without the consideration of the DT, the actual use of the Bei structure at the discourse level, the argument that the marked Chinese passive voice, Bei structure is not the preferred is easily suggested. On the contrary, if this study had examined the Chinese EFL learners' production of passive voice only at the discourse level (DT), the results would firmly suggest that the EFL learners use number of Bei structure in their writing, the L2 English to L1 Chinese effect in the English Level 2 participants at the sentence level would have been unnoticed. In a word, the methodological implication of this study shows the importance of taking different language levels of analysis into consideration.

\subsubsection{Pedagogical Implication}

Previously, we have analyzed the manifestations of backward transfer, which proves the influence of backward transfer is just interfering, but it can also exert a positive effect on language learning. Therefore, in foreign language teaching, teachers should pay attention to balancing the explanation of similarities and differences between languages (Davies \& Pearse, 2002). By analyzing the similarities, we can increase learners' confidence and strengthen their determination in learning well. However, similarities are not easy to be perceived. Therefore, it is significant to give learners concrete directions to increase their meta-linguistic awareness (Stern, 1999). On the other hand, the contrasting linguistic patterns in Chinese and English need to be explicitly taught to L2 learners. For example, Chinese learners of English, especially those at the beginning level, will need to be taught the important distinction in English and Chinese: i.e., Bei structure (passive voice) is the unmarked form in English, but it is a marked one in Chinese. It is unlikely that language learners will master these subtle language-specific uses unless efforts are directed at raising their meta-linguistic and cross-linguistic awareness (Ellis, 1994).

\subsection{Limitation}

The present study has discussed the existence of backward transfer in Chinese learners of English in China, the relations between backward transfer and learners' L2 and L1 proficiency. However, it seems that limitations are inevitable regarding methodology, namely, data collection and analysis, the choice of the English sentences in STT.

Considering the eligibility of the questionnaire, the author only chooses a total of 60 freshmen in this study. Among the 60 participants, they are further divided into three proficiency levels with 20 participants on each level. Although the number of 20 participants on proficiency level meets the minimal requirement for effective statistical inference (Demaris, 1992), the amount of the data received is not substantial enough to make the findings more convincing.

Moreover, in regard to the backward transfer, there are also some disputes. This study is based on the multi-competence theory, which is related to human mind. Within my limits, I can only study the output of the learners to study their minds. However, it is much harder to determine whether their Chinese output is really influenced by the second language in their minds, as there are various factors that may affect the Chinese output.

Limitations of the present study also harbor some opportunities for follow-up researches. The subjects of this study are the Chinese learners of English in China. It is hoped that such findings may be potentially applicable to the research in the similar field, namely, studies of other countries' L2 users. Thus, it is possible for us to have a better understanding of the general features of the backward transfer. If possible, longitude study needs challenging. In addition, quantitative methodology may enable the research with sufficient data. Meanwhile, this study just mentions the multi-competence theory. Actually, there are many other models regarding the relationships between the two languages.

\section{Acknowledgment}

This research was supported by the China Scholarship Council; Humanities and Social Sciences Foundation in the Education Department of Henan Province (2016-qn-165). The 12th Five-year Plan of Henan Science of Education (2015-JKGHYB-0063); The Teaching Reform Project in Henan Polytechnic University (2015JG007; 2015JG086). 


\section{References}

Abu-Rabia, S., Shakkour, W., \& Siegel, L. (2013). Cognitive Retroactive Transfer (CRT) of Language Skills among Bilingual Arabic-English Readers. Bilingual Research Journal, 36(1), 61-81. http://dx.doi.org/10.1080/15235882.2013.775975

Balcom, P. (1995). Argument structures and multi-competence. Linguistica Atlantica, 17, 1-17.

Balcom, P. (2003). Cross-linguistic Influence of L2 English on Middle Constructions in L1 French. In V. Cook (Ed.), Effects of the Second Language on the First (pp. 168-192). Clevedon: Multilingual Matters Publishing.

Bialystok, E. (2001). Bilingualism in development. Cambridge: Cambridge University Press. http://dx.doi.org/10.1017/CBO9780511605963

Carson, J. E., \& Kuehn, P. A. (1992). Evidence of transfer and loss in developing second language writers. Language Learning, 42, 157-179. http://dx.doi.org/10.1111/j.1467-1770.1992.tb00706.x

Cook, V. J. (1991). The Poverty-of-the-stimulus argument and multi-competence. Second Language Research, 7(2), 103-117. http://dx.doi.org/10.1177/026765839100700203

Cook, V. J. (1992). Evidence for multicompetence. Language Learning, 42, 557-591. http://dx.doi.org/10.1111/j.1467-1770.1992.tb01044.x

Cook, V. J. (2000). Is transfer the right word? Paper presented at the 7th International Pragmatic Conference, Budapest.

Cook, V. J. (2002a). Background to the L2 user. In V. J. Cook (Ed.), Portraits of the L2 user (pp. 1-28). Clevedon, UK: Multilingual Matters.

Cook, V. J. (2002b). Portraits of the L2 user. Clevedon, UK: Multilingual Matters.

Cook, V. J. (2003a). Introduction: The changing L1 in the L2 user's mind. In V. J. Cook (Ed.), Effects of the second language on the first (pp. 1-6). Clevedon: Multilinual Matters. http://dx.doi.org/10.1017/cbo9780511806766.003

Cook, V. J. (2003b). Effects of the second language on the first. Clevedon: Multilinual Matters.

Cummins, J. (1976). The influence of bilingualism on cognitive growth: A synthesis of research findings and explanatory hypotheses. Working Papers on Bilingualism, 9, 1-43.

Cummins, J. (1979) Linguistic interdependence and the educational development of bilingual children. Review of Educational Research, 49, 222-251. http://dx.doi.org/10.3102/00346543049002222

Davies, P., \& Pearse, E. (2002). Success in English teaching. Shanghai: The foreign language education publisher.

Demaris, A. (1992). Logit modeling: Practical applications. (Sage University Paper Series on Quantitative Applications in the Social Sciences, series no. 07-086). Newbury Park: Sage. http://dx.doi.org/10.4135/9781412984836

Du, R. (1993). Comparison between the Chinese notional passive and the English passive. In H. Wang (Ed.), Yinghan duibi lunwenji. Beijing: Beijing Language Institute Press.

Ellis, R. (1985). Understanding second language acquisition. London: Oxford University Press.

Ellis, R. (1994). The study of second language acquisition. London: Oxford University Press.

Grosjean, F. (2001). The bilingual's language modes. In J. Nicol (Ed.), One mind, two languages: Bilingual language processing (pp. 1-25). Oxford: Blackwell.

Kecskes, I. \& Papp T. (2000). Metaphorical Competence in Trilingual Language Production. In J. Cenoz \& U. Jessner (Eds.), Acquisition of English as a Third Language (pp. 99-120). Clevedon: Multilingual Matters.

Kecskes, I., \& Papp, T. (2000). Foreign language and mother tongue. Hillsdale, NJ: Lawrence Erlbaum.

Kecskes, I., \& Papp, T. (2003). How to Demonstrate the Conceptual Effect of L2 on L1? In V. J. Cook (Ed.), Effects of the Second Language on the First (pp. 247-265). Clevedon: Multilingual Matters Publishing.

Kellerman, E., \& Sharwood Smith, M. (1986). Crosslinguistic influence in second language acquisition. New York: Pergamon Institute of English.

Laufer, B. (2003). The Influence of L2 on L1 Collocational Knowledge and on L1 Lexical Diversity in Free 
Written Expression. In V. Cook (Ed.), Effects of the Second Language on the First (pp. 19-31). Clevedon: Multilingual Matters Publishing.

Liu, H., Bates, E. A., \& Li, P. (1992). Sentence interpretation in bilingual speakers of English and Chinese. Applied Psycholinguistics, 13, 451-484. http://dx.doi.org/10.1017/S0142716400005762

Odlin, T. (1989). Language transfer. Cambridge: Cambridge University Press. http://dx.doi.org/10.1017/CBO9781139524537

Papp, T. (1991). The study of the interrelation of the mother tongue development and foreign language learning in a longitudinal experiment. Unpublished dissertation for the candidate degreee of the Hungarian Academy of Sciences, Budapest.

Pavlenko, A. (2003). "I Feel Clumsy Speaking Russian": L2 Influence on L1 in Narratives of Russian L2 Users of English. In V. J. Cook (Ed.), Effects of the Second Language on the First (pp. 32-61). Clevedon: Multilingual Matters Publishing.

Pavlenko, A., \& Jarvis, S. (2002). Bidirectional transfer. Applied Linguistics, 23, 190-214. http://dx.doi.org/10.1093/applin/23.2.190

Selinker, L. (1972). Interlanguage. International Review of Applied Linguistics, 10, 209-231. http://dx.doi.org/10.1515/iral.1972.10.1-4.209

Sharwood, S. M. (1992). On first language loss in the second language acquirer: Problems of transfer. In S. M. Gass \& L. Selinker (Eds.), Language transfer in language learning (pp. 222-231). Rowley: Newbury House. http://dx.doi.org/10.1075/lald.5

Stern, H. H. (1999). Fundamental concepts of language teaching. Shanghai: Shanghai Foreign Language Teaching and Research Press.

Su, I-Ru. (2001). Transfer of sentence processing strategies: A comparison of L2 learners of Chinese and English. Applied Psycholinguistics, 22, 83-112. http://dx.doi.org/10.1017/s0142716401001059

Thomson, S., \& Kaufman, T. (1988). Language contact, creolizaion, and genetic linguistics. Berkeley: University of California Press.

Wang, G. Y. (2006). Understanding Language Transfer from Nominal Construstions Beyond IP. Foreign Lauguage Education, 5, 40-44.

Wang, L. (1985). Zhongguo xiandai yufa (Modern Grammar of China (II)). Beijing: The Commercial Press.

Wang, Z. J. (2004). A cognitive contrastive study of English and Chinese passives. Shanghai: Shanghai Foreign Language Education Press.

Wang, Z. J., \& Yang, X. Q. (2002). A Corpus-based Contrastive Study of English and Chinese Passives and its Cognitive Interpretation. Shandong Foreign Languages Journal, 3, 27-28.

Weinreich, U. (1953). Language in contact: Findings and problems. New York: Linguistic Circle of New York.

Xiong X. L., \& Wang, Z. J. (2002). On prototypes of passive voice. Foreign Language Research, 1, 19-23.

Zhang, J. Y., \& Xue, Ch. M. (2006). The L2 Effect in Direct Translation. Foreign Language and Literature Studies, 2, 113-117.

Zhang, Zh. B. (1995). A new English Grammar. Shanghai: Shanghai Foreign Language Education Press.

Zinszer, B. D., Chen, P., Wu, H., Shu, H., \& Li, P. (2015). Second language experience modulates neural specialization for first language lexical tones. Journal of Neurolinguistics, 33, 50-66. http://dx.doi.org/10.1016/j.jneuroling.2014.09.005 


\section{Appendix A}

\section{The Frequency and Percentage of Structure Use}

\begin{tabular}{|c|c|c|c|c|c|}
\hline Sentence & $\begin{array}{l}\text { Frequency of non-Bei } \\
\text { structure use }\end{array}$ & $\begin{array}{l}\text { Percentage of non-Bei } \\
\text { structure use }(\%)\end{array}$ & $\begin{array}{l}\text { Frequency of } \\
\text { Bei structure use }\end{array}$ & $\begin{array}{l}\text { Frequency of } \\
\text { correct use }\end{array}$ & $\begin{array}{l}\text { Percentage of } \\
\text { correct use (\%) }\end{array}$ \\
\hline 1. He was criticized today. & 18 & 18 & 82 & 82 & 82 \\
\hline 2. No sound was heard. & 97 & 97 & 3 & 83 & 85.6 \\
\hline 3. The problem was solved. & 59 & 59 & 15 & 57 & 96.6 \\
\hline 4. The house is being built. & 79 & 79 & 9 & 63 & 79.7 \\
\hline 5. This must be done at once. & 87 & 87 & 7 & 84 & 96.6 \\
\hline 6. I was given that thing. & 66 & 66 & 13 & 51 & 77.3 \\
\hline 7. The thief was caught last night. & $12(10$ active $)$ & 12 & 18 & 2 & 16.67 \\
\hline 8. Teachers may be asked questions. & 45 & 45 & 17 & 18 & 40 \\
\hline 9. What language is spoken there? & 100 & 100 & 1 & 96 & 96 \\
\hline 10. What he said was understood by others. & 69 & 69 & 10 & 65 & 94.2 \\
\hline 11. That young man cannot be relied upon. & 66 & 66 & 11 & 57 & 86.4 \\
\hline 12. Finally, my book was published. & 65 & 65 & 14 & 62 & 95.4 \\
\hline 13. You are wanted on the phone. & 94 & 94 & 4 & 85 & 90.41 \\
\hline 14. The violin was made by my father. & 90 & 90 & 5 & 66 & 73.3 \\
\hline 15. The chicken was killed. & 12 & 12 & 19 & 1 & 8.3 \\
\hline $\begin{array}{l}\text { 16. Children should be taught to speak the } \\
\text { truth. }\end{array}$ & 66 & 66 & 12 & 65 & 98.5 \\
\hline 17. The window needs to be repaired. & 87 & 87 & 8 & 86 & 98.9 \\
\hline 18. Those characters were written by him. & 97 & 97 & 2 & 71 & 73.2 \\
\hline $\begin{array}{l}\text { 19. I was taught that two sides of a triangle } \\
\text { were greater than the third. }\end{array}$ & 58 & 58 & 16 & 49 & 84.5 \\
\hline $\begin{array}{l}\text { 20. It is well-known that compass was } \\
\text { invented in China almost four thousand } \\
\text { years ago. }\end{array}$ & 90 & 90 & 6 & 80 & 88.9 \\
\hline
\end{tabular}

\section{Copyrights}

Copyright for this article is retained by the author, with first publication rights granted to the journal.

This is an open-access article distributed under the terms and conditions of the Creative Commons Attribution license (http://creativecommons.org/licenses/by/3.0/). 